\title{
Management Tasks of Assessing Subjective Road Traffic Noise With Using Acoustic Maps-A New Approach
}

\author{
Waldemar Paszkowski, Dorota Palka \\ Silesian University of Technology, Silesia, Poland
}

\begin{abstract}
At present, acoustic maps are used in management tasks of assessing the acoustic climate of the environment. The methods of modeling and simulation of noise assessment indices are used for this purpose. These indicators represent the quantitative spatial distribution of the sound level. Research on the perception of sounds has been carried out for many years and it has been found out that subjective acoustic impressions are of significant importance. This paper proposes a quantitative and qualitative approach to the assessment of noise in the urbanized environment using acoustic maps. The features of sound quality and their importance in the modeling of noise annoyance assessment have been described. Acoustic measurements were made on the example of the selected case study in the environment. The results of modeling physical indicators of road noise in the environment with the use of acoustic maps are presented. Based on the registered acoustic measurements, the results of the sound quality features of the acoustic signals in the time and frequency domain are presented below. The determined values of sound quality features are a valuable source of information in the field of noise perception assessment. A model for assessing road noise has been proposed. It includes sound quality features which can be used in acoustic maps. As part of the discussion of the results, it was found that the obtained results of quantitative and qualitative analysis of the acoustic signal parameters can be the basis for the development of the road traffic noise annoyance assessment model using acoustic maps technology.
\end{abstract}

Keywords: acoustic climate, acoustic map, noise annoyance, noise management, sound features

\section{Introduction}

One of the important tasks of noise management in the urbanized environment is to shape the acoustic climate. Measurement methods and simulations of acoustic parameters for the needs of identification and assessment of the acoustic climate of the environment are commonly used in this respect (Batko \& Bal-Pyrcz, 2017). The basis for making decisions regarding the use of solutions limiting or minimizing noise in the environment is the assessment of its acoustic climate. Depending on the needs, the tasks of noise management

Acknowledgements: This article is the result of research conducted at the Institute of Production Engineering, Faculty of Organization and Management, Silesian University of Technology, within the statutory work entitled "Shaping Intelligent Production Methods, Work and Living Environments in the Context of Production Engineering Challenges" (symbol 13/030BK 18/0039).

Waldemar Paszkowski, Ph.D., Eng., Institute of Production Engineering, Faculty of Organization and Management, Silesian University of Technology, Silesia, Poland.

Dorota Palka, Ph.D. student, M.Sc., Eng., Institute of Production Engineering, Faculty of Organization and Management, Silesian University of Technology, Silesia, Poland.

Correspondence concerning this article should be addressed to Waldemar Paszkowski, Roosevelta 26, Zabrze 41-800, Silesia, Poland. 
in the environment may be targeted at noise reduction solutions in the scope of limiting, e.g., noise emission of sources, transmission of acoustic energy on its transferring road or immission to specific areas of the environment.

In accordance with the applicable legal regulations (Regulation of the Minister of the Environment, 2012), the applied approach to noise management tasks in the environment is a quantitative assessment of the noise hazard caused by the impact of noise sources.

On the basis of the obtained value of the noise rating indicator and depending on the need for noise reduction, it is possible to lower the value from the above-average level to the acceptable level. For this purpose, in the field of protection against noise in the implementation of the long-term policy, long-term indicators of sound level $\mathrm{L}_{\mathrm{den}}, \mathrm{L}_{\text {night }}$ are used. We also deal with the problem of noise reduction and the choice of the right solution when the value of the equivalent sound level $\mathrm{L}_{\text {Aeq }}$ is exceeded in the daily time interval. Then, the problem of noise reduction is more local and refers to the type of land with a particular method of management.

The legal basis for undertaking noise management tasks in the external environment of national regulations is the Act of April 27, 2001. The statutory provisions refer to the tasks of creating and using strategic acoustic maps. In addition, the requirements relating to the assessment and management of noise levels in environments regarding the preparation of strategic noise maps listed in Directive 2002/49/EC specify, among others, the scope of activities related to the environmental protection from excessive noise. The recommended in Directive 2002/49/EC noise calculation methods which are used in the creation of strategic noise maps refer to, among others, sources of road noise. The results obtained in the implemented target project- "Development of a national system for the creation and exploitation of digital acoustic maps of large and medium cities for the purpose of professional planning and training purposes" in the field of validation studies of the road noise source model (according to the NMPB method) for urban conditions showed the compliance of measurement results and calculations, provided that full information on traffic conditions is gathered.

According to the authors of this article, a quantitative approach to assessing the acoustic climate in the environment is insufficient and limited, as it does not take into account the subjective aspects of sound perception. In this sense, the current assessment method requires extension and supplementation with a quality approach. The issue discussed in this article is a proposal to apply a quantitative and qualitative approach to noise pollution assessment for the purpose of supporting road noise management tasks.

The presented proposal is based on modeling road traffic annoyance with the use of acoustic map technology as a way of assessing the environmental acoustic climate. The assumption of the assessment method includes the psychophysical features of sound.

\section{The Issue of Sound Quality Features in the Assessment of Noise Annoyance}

In an urbanized environment, mobile noise sources are generally road vehicles. The negative effect of vehicle traffic is the occurrence of variations in acoustic energy emission over time. The variability of this energy depends not only on the stream and the generic structure of vehicles, but also on the type and condition of the road surface. The problem of vehicle noise impact is related not only to the emission of the source itself, but also to the relation of the variables present between the source and the recipient. The areas that are particularly exposed to the negative impact of vehicles in the urbanized environment are residential areas. 
The objective representation of the sound perception process includes the basic physical parameters of the description of the acoustic signal such as: sound level, spectrum, tonality, impulsivity, duration, and time structure of the sound.

In addition to the psycho-acoustic features, the subjective assessment of sounds also consists of non-acoustic factors, which include, among others: mood, context, emotions, place, and attitude.

Putting together objective and subjective sound evaluation parameters with acoustic factors may constitute an approximation of noise annoyance. In this sense, noise annoyance assessment cannot be expressed only by sound level. Variables accompanying noise annoyance outside the dimension of the nature of noise can be reduced to distortions in the perception process containing different context and variable individual characteristics.

According to Directive 2002/49/EC, in the evaluation of noise annoyance, the $\mathrm{L}_{\mathrm{den}}$ index is used, which is defined as the degree of noise nuisance for the community in a given area. The development of noise annoyance evaluation has focused on linking psychoacoustic measures of sound quality assessment with quantitative noise indicators. The obtained results in this respect indicate the importance of psychophysical aspects in noise annoyance. In this approach, the research focuses on the inclusion of sound quality features, i.e., loudness (N), sharpness (S), roughness (R), fluctuation strength (FS), while also referring to the quantitative rating indicator of noise sources $-\mathrm{L}_{\text {Aeq. }}$. The attempts to include the above measures in the assessment of annoyance caused by the influence of noise sources determine the objective or psychoacoustic model of noise nuisance, taking into account the combination of features of sound quality assessment (Fastl \& Zwicker, 2007).

The basic psychoacoustic feature of evaluating the variables of annoyance of time-varying sounds is loudness of time-varying, which is a standardized feature (DIN 45631/A1, 2010). Loudness as the basic feature of the sound quality evaluation shows the non-linearity of the sound level as a function of frequency and sound level. The loudness formation for the time-varying sounds varies with the sound level and depends on the duration of the sound. In models used for loudness assessment, the percentiles of loudness are assumed, i.e.: $\mathrm{N}_{5}$, $\mathrm{N}_{10}$ in relation to the duration of sound.

For non-stationary sound signals, models developed by Zwicker and Fastl (1999) and by Glasberg and Moore (2002) were proposed. The determination of $\mathrm{N}_{10}$ or $\mathrm{N}_{5}$ using the above mentioned models leads to different results for the same signals (Preis \& Kaczmarek, 2010).

The applied sound quality techniques, such as, sharpness and tonality, are standardized only for stationary signals. Other features, i.e., roughness and fluctuation strength, are determined based on accepted calculation models, however, these are not standardized features.

The developed quantitative combination of sound quality features has been used in predicting psychoacoustic annoyance of sound emission (Fastl \& Zwicker, 2007).

In the model adopted above, loudness is the dominant feature of noise annoyance. At the same time, the assumed percentile loudness value $\mathrm{N}_{5}$ was considered significant in the assessment of sound quality.

Two sound levels with equal sound pressure levels, but different frequencies correspond to different loudness impressions (Gallego, 2009). The perception of sounds depending on the time structure, amplitude changes or frequency can also be different even with the loudness unchanged.

The problem of annoyance of noise sources' influence should be considered at the simultaneous connection of the following issues: noise, context, and person (Report the "Genlyd", 2007). 
The dynamic nature of the impact of various noise sources, the subjective aspect of the place of perception of sounds, and the multiplicity of factors accompanying this process mean that despite many attempts, no universal noise annoyance assessment model has been developed. In this sense, the existing models do not take into account the coexistence of quantitative and qualitative variables (factors) in the assessment of sound, emotions, contexts accompanying the process of perceiving sound.

In the applied calculation procedures, the estimation of noise hazard with the use of acoustic maps does not take into account the subjective impressions of perception of acoustic signals. In particular, the parameters determined in the acoustic maps are limited only to the quantitative values of the environment exposed to the impact of noise sources, i.e., $\mathrm{L}_{\mathrm{Aeq}}, \mathrm{L}_{\mathrm{den}}, \mathrm{L}_{\text {night }}$. One of the problems limiting the use of sound quality in acoustic maps is, among others, the lack of modeling in the spatial distribution of the environment. It should be noted that there is also the technical possibility of linking the quantitative parameters of the sound assessment with the sound quality assessment features in the acoustic maps at the modeled point of emission/immission.

The approach used lacks a method for simulating noise annoyance assessment in acoustic maps, which would take into account the direct relationship between physical and psychoacoustic parameters of the sound.

The results of undertaken research on the evaluation of the distribution of sound quality characteristics in the environment, depending on the applied methods, show a varied and non-linear variability as a function of the distance from the source (Genuit \& Fiebig, 2006), however, there is no known mathematical formula describing the formation of the variation distribution of these features of the environmental space. The evaluation of the value distribution sound quality features is related to the measuring point in the space in which the acoustic signal is registered. This means that the assessment of the shaping of the sound quality features in the domain of time or frequency is assigned only to the space point. At the current stage of research, this constitutes a limitation on the implementation of simulation tasks and forecasts the spatial distribution of sound quality assessment features using acoustic map technology.

\section{Management of Acoustic Climate Oriented to the Psychophysical Features of Sound}

One of the purposes of creating strategic acoustic maps is among others traffic noise management in urban areas. On the one hand, they enable obtaining information about the condition of the acoustic climate. On the other hand, they aide to make decisions on the selection of noise reduction solutions. They also allow obtaining information on the amount of people exposed to excessive noise due to the impact of various types of noise sources.

Acoustic maps are also a useful tool for conducting statistical analyzes using the relationship between modeled objects and noise indicators. The division of discretization into basic elements, usually rectangular, is assumed for the studied areas. In accordance with the above, the correlation between the indicators mapping the correlation of the acoustic parameters distribution with the values describing the variables of the environmental objects is used. The results obtained in this area indicate that urban morphology has a significant impact on, among others, the loudness of road noise. The assessment of noise pollution includes statistical correlations among the noise level of the facades, the loudness of traffic and the density of population (Salomons \& Berghauser, 2012).

The undertaken research in the field of road traffic noise forecasting is based on quantitative regression or correlation models that take into account the impact and heterogeneity between neighboring geographical areas 
(Lesage \& Pace, 2009). The use of spatial analysis allows obtaining information and assessing the relations between the urban form indicators and the noise level.

For many years, researchers have been trying to develop a holistic approach to assessing the acoustic environment in the field of soundscape mapping. These maps are based on simultaneous consideration of the physical and perceptual factors of sound sources. They extend the current approach to noise mapping by taking into account the context of perception of sounds in areas of various purposes, e.g., recreational, residential, commercial centers. In order to obtain information from residents about the perception of different types of sounds, questionnaires are used to assess, for example, natural sounds, sounds produced by human activity or road noise. The quality of sound perception is most often evaluated using adjectives and the scale in relation to the day-evening season. Obtained results of one of the tests in one area showed Pearson's correlation over 0.5 perceived loudness from $\mathrm{L}_{\mathrm{Aeq}}$ for sources of road noise in each time interval (Hong \& Jeon, 2014).

In accordance with the guidelines of the European Environment Agency (EEA) in the management of areas focused on "noise quality" in the environment, it is recommended to integrate the following methods: noise mapping, sound level measurement, soundscape approach, and experts' assessment (Aletta \& Kang, 2015). Such an approach which approximates the soundscape of the venue using individual responses can be integrated in mapping tasks, i.e., acoustic maps, sound maps, and landscapes maps.

The idea of creating psychoacoustic maps already appeared in 2006, and it assumed linking conventional acoustic maps with the psychoacoustic aspects of sound perception in the environment. This need is still an unresolved problem in developing a model that does not take into account only the relation of physical and psychoacoustic aspects of sound perception, signal processing, in relation to variables related to their information content and assessment of impressions (Genuit \& Fiebig, 2006).

\section{Supporting Road Noise Assessment Tasks Using Acoustic Maps-A Case Study}

\section{Modeling of Physical Indicators of Noise Assessment}

We carried out a simulation analysis of $\mathrm{L}_{\text {Aeq }}$ distribution variants for the selected urbanized area which may be threatened with road noise sources. In this analysis, we used acoustic maps. Based on the acquired data, we prepared the terrain model along with models of accompanying objects. The input data for the simulation were the values of the measured intensity of vehicles (including trucks). These values were measured for each road lane within one hour for daytime. At the same time, the acoustic measurements of the SVAN 971 meter were carried out at three representative reference points P1, P2, P3 (Figure 1) corresponding to the traffic measurements..
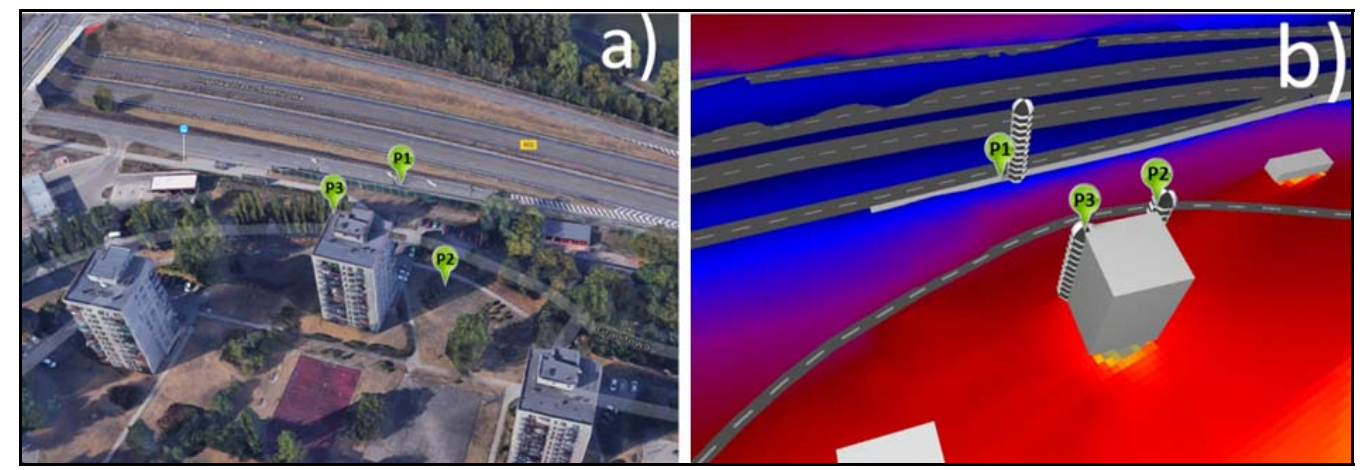

Figure 1. Illustration of the studied area, acoustic map of the $\mathrm{L}_{\text {Aeq }}$ (A) distribution (Paszkowski \& Dąbrowski, 2017). 
We made the following assumptions in modeling the features of the objects of the studied area, i.e.:

- Variant 1 -we assigned the real/measured values of sound absorption coefficients to the object models,

- Variant 2-we assigned the identical sound absorption coefficient $\alpha=1$ to the object models,

- Variant 3-we assigned the identical sound absorption coefficient $\alpha=0$ to object models.

Thanks to these variants, we obtained information about the division of acoustic energy into direct and reflected sounds at the reference sounds. As a result of sound level simulations for the variants mentioned, the following $\mathrm{L}_{\text {Aeq }}$ results were obtained (Table 1).

Table 1

Summary of Information on Reference Points

\begin{tabular}{lllll}
\hline Point number & Position height $/$ measured $\mathrm{L}_{\mathrm{Aeq}}$ value & Variant 1 & Variant 2 & Variant 3 \\
\hline P1 & $1.7[\mathrm{~m}]$ & $78.4[\mathrm{~dB}(\mathrm{~A})]$ & $78.2[\mathrm{~dB}(\mathrm{~A})]$ & $79.2[\mathrm{~dB}(\mathrm{~A})]$ \\
& $77.1[\mathrm{~dB}(\mathrm{~A})]$ & & & \\
P2 & $1.7[\mathrm{~m}]$ & $61.7[\mathrm{~dB}(\mathrm{~A})]$ & $59.5[\mathrm{~dB}(\mathrm{~A})]$ & $68.5[\mathrm{~dB}(\mathrm{~A})]$ \\
& $58.4[\mathrm{~dB}(\mathrm{~A})]$ & & & \\
P3 & $27[\mathrm{~m}]$ & $71.5[\mathrm{~dB}(\mathrm{~A})]$ & $71.4[\mathrm{~dB}(\mathrm{~A})]$ & $72.2[\mathrm{~dB}(\mathrm{~A})]$ \\
\hline
\end{tabular}

Source: Paszkowski \& Dąbrowski (2017).

Particular variants were assigned values of the soil absorption coefficient $\mathrm{G}$, respectively in the order of variants (Table 1 ): $\mathrm{G}=0.7 ; \mathrm{G}=1 ; \mathrm{G}=0$.

After substituting the values to (1) using the simulation of sound propagation and information on the features of objects, we obtained the following values of the reflectance (Table 2).

$$
\begin{gathered}
\beta_{s r}=\frac{\sum_{i=0}^{i=n} I_{o d b}}{\sum_{i=0}^{i=n} I_{p a d}} \\
I_{o d b \text { —energy of reflected waves }\left[\frac{W}{m^{2}}\right]} \\
I_{p a d \text { —energy of falling waves }\left[\frac{W}{m^{2}}\right]}
\end{gathered}
$$

Table 2

$\beta_{s r}$ Shaping Results at the Examined Reference Points

\begin{tabular}{ll}
\hline Point number & $\beta_{s r}$ \\
\hline P1 & 1.26 \\
P2 & 7.94 \\
P3 & 1.20 \\
\hline
\end{tabular}

Source: Paszkowski \& Dąbrowski (2017).

The analysis of the obtained results of energy simulation of both absorbing and reflected waves (Table 2) shows that the relation of reflected acoustic energy to the energy of incident waves is the highest for the examined point P2 when compared to points $\mathrm{P} 1$ and $\mathrm{P} 3$. According to the authors, the spatial position of point 
P2 relative to road sources, acoustic barriers and the building has a decisive influence on the obtained value. At the remaining points $\mathrm{P} 1$ and $\mathrm{P} 3$, the proportion of this relation was at a similar level, although the location of these points relative to the sources and acoustic barriers was significantly different. The assumed value of the $\mathrm{G}$ coefficient was of less importance to the obtained results. This also means that at point P2 the wave energy caused by reflections in relation to the energy of incident waves is significantly higher than in the case of other points.

\section{Features of Sound Quality of Acoustic Signal}

At points $\mathrm{P} 1-\mathrm{P} 3$, apart from the measurement of $\mathrm{L}_{\mathrm{Aeq}}$, we registered acoustic signals (single channel). On this basis, the sound quality features were determined at the tested points in the time and frequency domain. To do this we used the Pulse Reflex system in version 21.0.0.567. Examples of sound quality features at points $\mathrm{P} 1-\mathrm{P} 3$ in the time domain are presented in Figure 2, Figure 3, respectively.

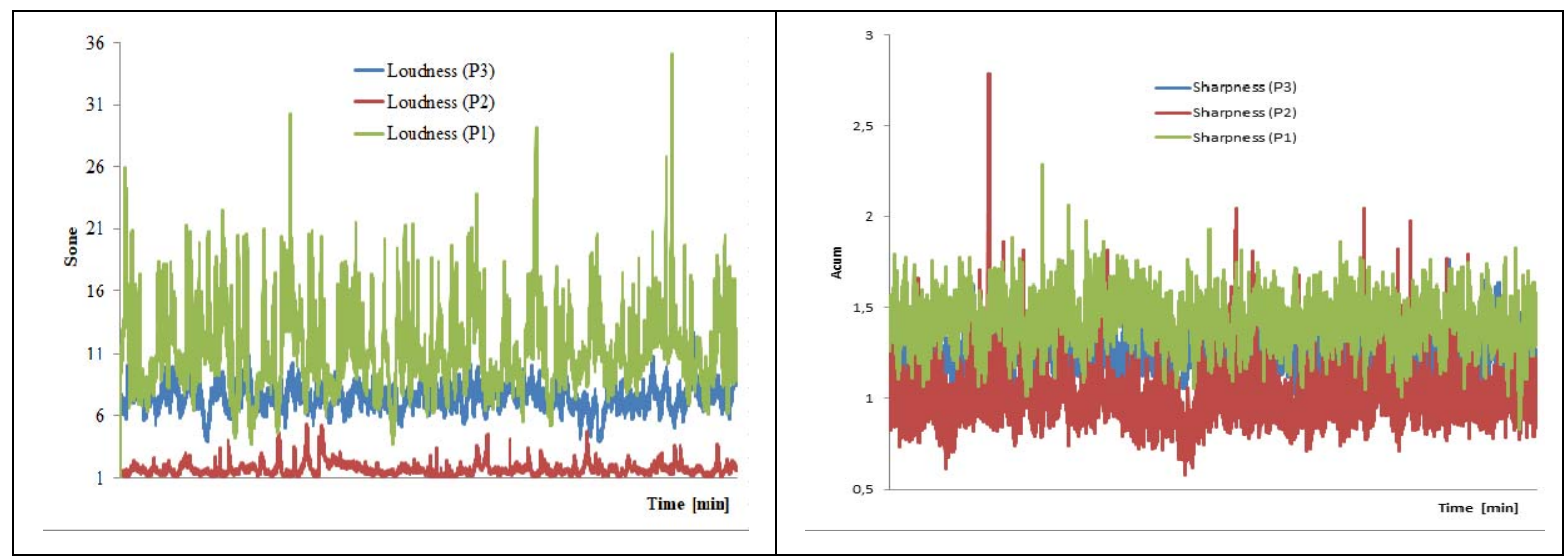

Figure 2. Characteristic of loudness and sharpness in time at the examined points. Source: own study.

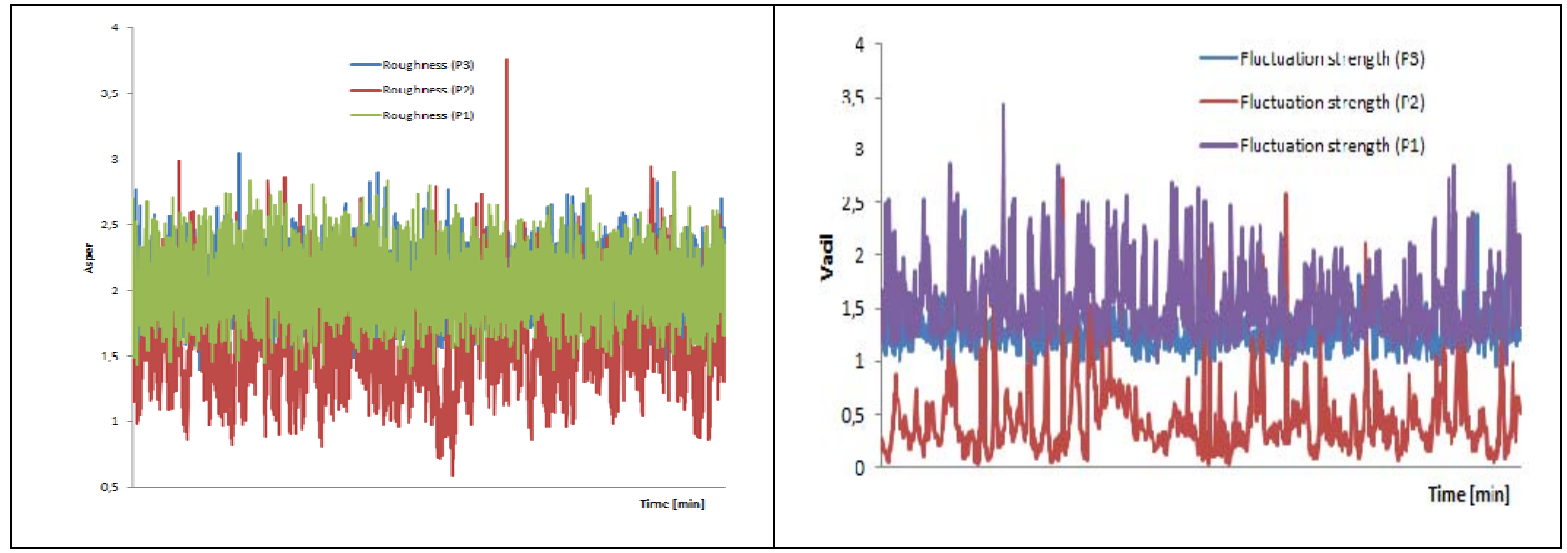

Figure 3. Characteristic of roughness and fluctuation strength in time at the examined points. Source: own study.

The comparison of the results of the level of sound quality features in time shows that the value of $\mathrm{L}_{\text {Aeq }}$ has a decisive influence on the distribution of their values. For P1, the average values of the sound quality features were the highest. We can notice that for short-term time segments, the obtained values of some of the sound quality features were the highest at the point P2. The analysis of measured signals also allows determining sound quality features at the examined points in the frequency bands (Figure 4 and Figure 5). This is important qualitative information about the assessment of the sound signal immission. 


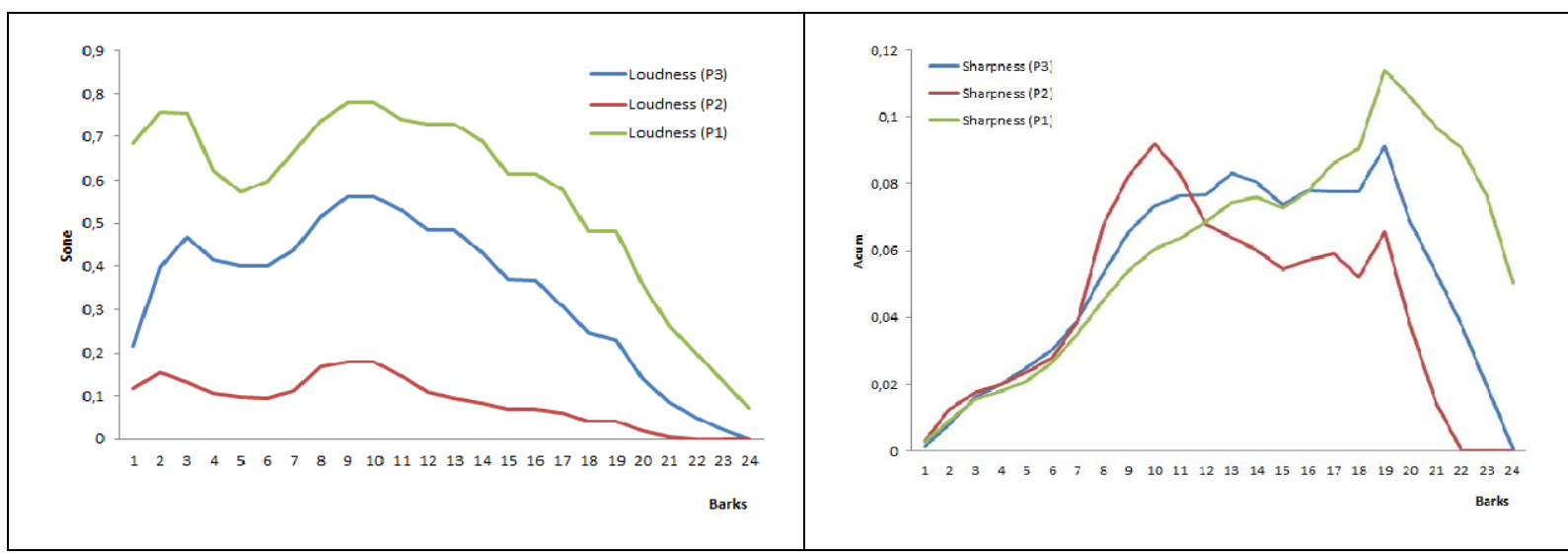

Figure 4. Characteristic of loudness and sharpness in the frequency domain barks at the examined points. Source: own study.

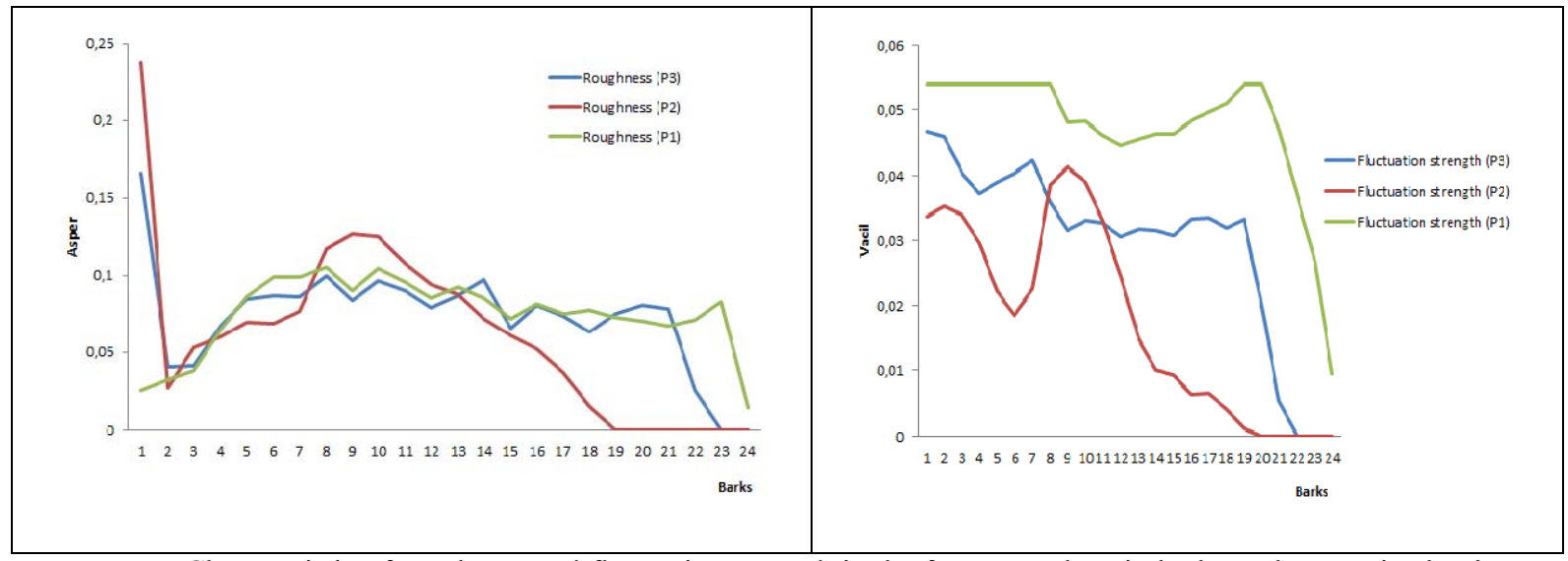

Figure 5. Characteristic of roughness and fluctuation strength in the frequency domain barks at the examined points.

Source: own study.

The obtained results in the frequency domain indicate the occurrence of local variations in the values of sound quality features in critical frequency bands, which is really important information in the assessment of acoustic signal perception. In the case of sharpness, roughness, and fluctuation strength, there are also local value enhancements of these characteristics for point P2, even though the point is located at a greater distance from the source than points $\mathrm{P} 1$ and $\mathrm{P} 3$.

\section{Proposal to Evaluate Road Noise Annoyance Using the Sound Quality Characteristics Model}

The analysis of the sound quality representation shows that currently there are no known methods for modeling sound quality characteristics in spatial distribution. The results of the representation of sound quality characteristics presented above allow for their assessment at the determined measuring points of the acoustic signal. In connection with the above, at the current stage of research, a punctual representation of the characteristics of sound quality features was assumed for time and frequency domain. The currently used method of quantifying the acoustic climate of the spatial distribution of sound level indicators in acoustic maps allows us to take into account the information about the formation of sound quality features.

It was assumed that due to the quantitative dimension of the qualities of sound, the proposed model will refer to one acoustic event corresponding to four selected points in the environment. In addition, it was assumed for the purpose of this model that the subjective assessments of noise perception at selected points for 
the above-mentioned acoustic events are known.

In the adopted model, it was proposed to assign sound quality characteristics in relation to $\mathrm{L}_{\text {Aeq }}$ for the purpose of determining noise annoyance assessment, i.e., linking subjective judgments of noise with sound quality values. The generalized form of such a model representing a selected acoustic event in time (for the analyzed points) takes the form:

$$
\left|A_{1,4}\right|=\left[S Q_{1,4 \times 4,1}\right] \cdot\left[w_{1,4}\right]
$$

where:

A - vector of average subjective noise ratings at selected points for the analyzed acoustic event;

$\mathrm{W}$ - matrix of relations between sound quality characteristics and subjective judgments of noise;

SQ — sound quality features, i.e., loudness (N), sharpness (S), roughness (R), strength fluctuation (FS).

After developing, the elements of the equation will take the form:

$$
\left|\begin{array}{l}
A_{1} \\
A_{2} \\
A_{3} \\
A_{4}
\end{array}\right|=\left[\begin{array}{llll}
N_{1} & S_{1} & R_{1} & F S_{1} \\
N_{2} & S_{2} & R_{2} & F S_{2} \\
N_{3} & S_{3} & R_{3} & F S_{3} \\
N_{4} & S_{4} & R_{4} & F S_{4}
\end{array}\right] \cdot\left[\begin{array}{l}
w_{1} \\
w_{2} \\
w_{3} \\
w_{4}
\end{array}\right]
$$

In order to determine the weight values for the adopted points, the equation (4) will take the form:

$$
\left[w_{1,4}\right]=\left[S Q_{1,4 \times 4,1}\right]^{-1} \cdot\left|A_{1,4}\right|
$$

In order to determine the desired noise annoyance assessment, it is necessary to multiply the matrix of the equation (3), after the operation of normalization of subjective assessments and features of the $S Q_{1,4 \times 4,1}$ matrix. The above model can also be used to represent sound quality characteristics in the frequency domain. However, it requires the adoption of the value of sound quality characteristics in specific critical bands, due to the adopted evaluation model proposal.

An important advantage of the model is the ability to predict the vector $A_{1,4}$ (with the knowledge of the matrix of weights of the model $W_{1,4}$ ), after introducing the modification of the sound quality characteristics $S Q_{1,4 \times 4,1}$.

\section{Conclusion}

The article describes and presents a proposal for a quantitative and qualitative approach to the tasks in the management process of road noise hazard assessment. It was assumed that the road traffic noise assessment model in the environment should take into account the quantitative and qualitative assessment of sound perception.

The presented approach of the application of psychophysical features of sound in acoustic maps extends the applied method of noise assessment to subjective perception of noise and sound quality features. The technology of creating and exploiting acoustic maps using the presented approach allows for supporting tasks in the area of noise management in the environment.

The knowledge of information about the formation of psychophysical features of sound is of particular importance in noise management in urbanized housing areas. In particular, the advantage of the approach presented is to take into account the nature of sound perception in a noise-stricken environment. It should be 
noted that the proposed model includes subjective judgments of people threatened by noise for selected locations of the environment.

In further research, it will be interesting to verify the presented noise annoyance model, among others in terms of its sensitivity to the vocal value $\mathrm{N}_{5}$ and $\mathrm{N}_{10}$.

The inclusion of the proposed model of noise annoyance assessment for acoustic maps allows for effective support of task management in the field of noise monitoring and forecasting and it will also help select the appropriate noise reduction measures, with particular emphasis on the subjective aspects of noise.

The analysis of the possibilities of acoustic map technology in the tasks of assessing the road noise hazard with the use of the proposed assessment model has been presented for a selected urban city fragment.

As part of the quantitative assessment, the $\mathrm{L}_{\mathrm{Aeq}}$ indicator was simulated and noise acoustic energy distribution was calculated at selected points taking into account the absorbing properties of the modeled objects.

The determined values of sound quality characteristics in time and frequency domain are important information regarding the perception of noise. In further research, it will be reasonable to use advanced methods of acoustic signal processing (e.g., spectrogram, scalogram) in the time-frequency domain for the needs of sound quality assessment.

Ultimately, the obtained results of quantitative and qualitative analysis of the acoustic signal parameters can be the basis for the development of the road noise annoyance model in the environment using acoustic map technology.

\section{References}

Aletta, F., \& Kang, J. (2015). Sounscape approach integrating noise map ping techniques: a case study in Brighton, UK. Noise Mapp., 2, 1-12.

Batko, W., \& Bal-Pyrcz, R. (2007). Analysis of stochastic acoustical hazards in environment. Archives of Acoustics, 32(4) (supplement), 235-245.

DIN 45631/A1 Calculation of loudness level and loudness from the sound spectrum-Zwicker method-Amendment 1: Calculation of the loudness of time-variant sound, BeuthVerlag, 2010.

Directive 2002/49/EC of the European Parliament and of the Council of 25 June 2002 relating to the assessment and management of environmental noise.

Fastl, H., \& Zwicker, E. (2007). Psychoacoustics: Facts and models (3rd ed.). Berlin: Springer-Verlag.

Gallego, M. C. (2009). Evaluación de la Molestia Psicoacústica Centradaenla Aspereza, P. F. C. Escuela Politécnica Superior de Gandía.

Genuit, K., \& Fiebig, A. (2006). Psychoacoustics and its benefit for the Soundscape Approach. Acta Acustica, 92, 1-7.

Hong, J. Y., \& Jeon, J. Y. (2014). Soundscape mapping in urban context using GIS techniques. In Proceedings of Internoise (pp. 1-5). Melbourne, Australia, Novembre 16-19, 2014.

Lesage, J. P., \& Pace, R. K. (2009). Introduction to spatial econometrics. Boca Raton: CRC Press/Taylor \& Francis Group.

Paszkowski, W., \& Dąbrowski, M. (2017). The use of acoustic maps in modeling features of objects oriented on acoustic quality of the environment. In Proceedings of 17th International Multidisciplinary Scientific GeoConference. Informatics, GeoInformatics and Remote Sensing. Cartography and GIS, 17(23), 769-776.

Preis, A., \& Kaczmarek, T. (2010). Annoyance of time-varying road-traffic noise. Archives of Acoustics, 35(3), 383-393.

Report the "Genlyd" Noise Annoyance Model. Ministry of Science, Technology and Innovation AV 1102/07, 2007.

Rozporządzenie Ministra Środowiska z dnia 1 października 2012 r. zmieniające rozporządzenie w sprawie dopuszczalnych poziomów hałasu w środowisku (Dz.U. z 8 października 2012, poz. 1109)/(Regulation of the Minister of the Environment, 2012).

Salomons, E. M., \& Berghauser, M. (2012). Pont Urban traffic noise and the relation to urban density, form, and traffic elasticity. Landsc Urban Plan, 108(1), 2-16.

Ustawa z dnia 27 kwietnia 2001r. Prawo ochrony środowiska Dz.U.2017, poz. 519/(The Act of April 27, 2001). 